ORIGINAL RESEARCH ARTICLE

\title{
The Effects of Early first Sexual Intercourse amongst Lesotho Women: Evidence from the 2009 Lesotho Demographic and Health Survey
}

\author{
Tshaudi Motsima ${ }^{1 *}$ and Jean-Claude Malela-Majika ${ }^{2}$ \\ Department of Mathematics and Statistics, Tshwane University of Technology, Pretoria, South Africa ${ }^{1}$; Department of \\ Mathematics and Statistics, Tshwane University of Technology, Pretoria, South Africa ${ }^{2}$
}

*For correspondence: E-mail: MotsimaT@tut.ac.za; Phone: +27 123825911

\begin{abstract}
Age at first sexual intercourse may be a predictor of future sexual behaviour and an important indicator for exposure to HIV transmission. The purpose of the study is to establish risk factors associated with age at first intercourse among Lesotho women aged 15 to 49 years. The data used came from the 2009 Lesotho Demographic and Health Survey and probit models were applied for analysis. It was found that women who have had their first sexual intercourse at age 16 or below were at risk of being married at age 18 or below ( $<0.001)$, are likely not to make it to secondary school ( $p<0.001)$ and having the highest chance of not have known about the AIDS disease as compared to women who have had their sexual intercourse after the age of 16 years $(\mathrm{p}<$ 0.05). Delaying entry into sexuality could be safer and more secure to protect the sexual and reproductive health in young women. The more time women spend at school the less likely that they can engage in sexual intercourse at a young age (Afr. $J$ Reprod Health 2016; 20[2]: 34-42).
\end{abstract}

Keywords: Sexual intercourse, sexual debut, risk factor, HIV, AIDS

\section{Résumé}

L'âge au premier rapport sexuel peut être un indice de comportement sexuel futur et un indicateur important pour l'exposition à la transmission du VIH. Le but de l'étude est d'établir les facteurs de risque associés à l'âge au premier rapport sexuel chez les femmes du Lesotho âgées de 15 à 49 ans. Les données utilisées provenaient du 2009 et Enquête de 2009 sur la santé et la démographie de Lesotho et nous avons fait les analyses par les méthodes des probits. Il a été constaté que les femmes qui ont eu leur premier rapport sexuel à 16 ans ou au-dessous étaient à risque d'être marié à 18 ans ou plus jeunes (p <0,001), elles sont susceptibles de ne pas continuer leur scolarité jusqu'à à l'école secondaire $(\mathrm{p}<0,001)$ et ont la plus haute chance de ne pas avoir connaissance de la maladie du sida par rapport aux femmes qui ont eu leur relation sexuelle après l'âge de 16 ans $(p<0,05)$. Retarder l'entrée en sexualité pourrait être plus sûr de protéger la santé sexuelle et de la reproduction chez les jeunes femmes. Plus le temps que les femmes passent à l'école, moins il est probable qu'elles puissent se livrer à des rapports sexuels à un jeune âge. (Afr. J Reprod Health 2016; 20[2]: 34-42).

Mots-clés: rapports sexuels, début sexuel, facteurs de risque, VIH, SIDA

\section{Introduction}

Sexual intercourse is a sexual contact between individuals involving penetration, especially the insertion of a man's erect penis into a woman's vagina, typically culminating in orgasm and the ejaculation of semen ${ }^{1}$. It is common that sexual intercourse is initiated at a young age. For the purpose of this paper, young age refers to age 16 years or less and older age refers to ages above 16 years. Early sexual intercourse or early sexual debut refers to the individual entered into first sexual intercourse at age 16 or below and late sexual intercourse or late sexual debut refers to the individual entered into first sexual intercourse after the age of 16 years. Age at first sexual intercourse may be a predictor of future sexual behaviour and sexual risk. Children are exposed to sexual images through the media ${ }^{2}$. Worldwide, the technology in mobile phones is improving on a daily basis, children are able to download pornography videos and watch them, subsequently their desire for sex as well as the likelihood of engaging in sexual intercourse elevates. 
Eventually the majority of them end up engaging in sexual intercourse by portraying the actions from the pornography videos they have been exposed to. Social and peer pressure may arise from the portrayal of sex as glamorous and pleasurable while negative consequences and the responsibilities involved in sexual relationships are seldom portrayed ${ }^{2}$. Although more liberal attitudes of the society have influenced the behaviour of the current generation of young people, few studies have considered the views of young people themselves about early sexual intercourse even though they have to bear the consequences ${ }^{2}$.

Age at first sexual intercourse is a marker of behavioural and health risks ${ }^{3}$ and is an important indicator for exposure to heterosexual Human Immunodeficiency Virus (HIV) transmission ${ }^{4}$. HIV infection is typically transmitted through unprotected sexual intercourse ${ }^{5}$. During unprotected sex with an HIV+ person the virus binds with the cluster of differentiation 4 (CD4) receptors in the lining of the genital tracks or anal tract of the uninfected partner ${ }^{5}$. Furthermore, early sexual intercourse is associated with subsequent high-risk behaviours, including having multiple sexual partners, lower levels of condom use and increased likelihood of Sexually Transmitted Infections (STI) and unintended pregnancy ${ }^{6}$ which may result in long term health and social disadvantages ${ }^{2}$. Age at first sexual intercourse is more likely to be associated with extramarital sex, multiple sexual partners, low condom usage, higher risk of STI and $\mathrm{HIV}^{7}$. However, delaying first sexual intercourse does not necessarily mean there will be no risk(s) related to sexual behaviours in adulthood. Lesotho is amongst the Eastern and Southern African countries with the highest adult HIV prevalence ${ }^{8}$. In 2010, slightly more than 20,000 new HIV infections occurred in Lesotho and the HIV prevalence for adults (15 years or more) was $23.6 \%$ and women aged 15 to 24 years were reportedly eight times more likely than men to be HIV+ in Eastern and Southern Africa $^{8}$.

In Lesotho health related reports such as the
Lesotho Demographic and Health Survey of 2009 (LDHS 2009) reported on the point estimate (percentages and/or frequencies) of age at first intercourse ${ }^{9}$, but not the association between age at first intercourse and future potential risk behaviours. The age at which children enter into their first sexual intercourse is an important public health issue in that there is a high risk of contracting STIs and diseases and unwanted pregnancies. Little is known about the long term negative impact or consequences of committing into sexual intercourse at a young age. Establishing whether entering into sexual debut at a young age increases the risk of sexual behaviour in adulthood can help to optimise the resources and make priorities in health programmes.

In a cross sectional household study conducted in the rural areas of KwaZulu-Natal province in South Africa it was found that early age (younger than 16 years) at first sexual intercourse was strongly associated with having multiple sexual partners among men ${ }^{10}$. It was found that females who had early sexual debut (at age 16 years or below) were more likely to have multiple sexual partners than females who had late sexual debut ${ }^{4}$.

In the United States of America it was also found that age at first sexual intercourse was associated with sex education ${ }^{11}$. Adolescent females who had received sex education before first sex were less likely to have had sexual intercourse before age 15 years than females who had not received sex education before first $\operatorname{sex}^{11}$. However, sexually experienced females who had sex education before first sexual intercourse were more likely to have reported using some form of birth control at first sex than those who had not had sex education before first $\operatorname{sex}^{11}$.

The purpose of the study is to establish risk factors associated with age at first intercourse among Lesotho women aged 15 to 49 years. To date, little evidence addressing the issue focusing on women entering in sexual intercourse at a young age has been established in Lesotho. The findings of this study will provide an understanding of the consequences of entering into 
sexual intercourse at a young age in Lesotho.

\section{Methods}

\section{Data}

The data for this study was obtained from the LDHS 2009. The LDHS 2009 data contains information on the history of age at first sexual intercourse for women and was used for analysis. The LDHS 2009 is a nationally representative survey that was used for the collection of population-based data to inform the Health Sector Programme (2000-2009), evaluate strides made since the first LDHS that was conducted in 2004, set a baseline for new programmes and provide information for policy and strategic planning 9 . A total of 9,391 households covering 400 enumeration areas (EAs) were selected and 7,624 women aged 15 to 49 years and 3,317 men aged 15 to 59 years were interviewed ${ }^{9}$. Women were asked how old they were when they engaged into sexual intercourse for the first time 9 . Amongst others, the LDHS 2009 collected information of women on the following topics: background characteristics (age, education, employment); sexual activity; HIV/AIDS related knowledge; behaviour and behaviour related to other health issues ${ }^{9}$.

\section{Measures and data cleaning}

Women were asked whether they ever had sexual intercourse since they were born. Those who responded that they have had sexual intercourse were asked how old they were when they had sexual intercourse for the very first time. The dependent variable was created using this information. The dependent variable was coded as 1 if the woman had her first sexual intercourse at age 16 years or below and 0 if she had her first sexual intercourse after the age of 16 years.

The place of residence of the respondents was binary and it was coded as 0 if the respondents resided in the urban areas and as 1 if the respondents resided in the rural areas. The respondents were asked how old they were when they got married for the first time. Some women married only once and were still married to the same husband while others may have been divorced or widowed. Of those who were either divorced or widowed some of them remarried and others did not. This information was used to create the variable "Age at first marriage" and it was coded as 0 if the woman married for the first time at age above 18 years and it was coded as 1 if the woman married for the first time at age 18 years or below.

Education level was coded as 0 for higher education, 1 for secondary education, 2 for primary education and 3 for no education.

Women were asked whether they had sexual intercourse with any other person apart from the person they usually have sex with (i.e. husband/boyfriend/sex partner, etc.) in the last 12 months prior to the survey date. They responded with either yes or no. If they responded that they had sexual intercourse with another person other than their regular sexual partner they then had to indicate the number of people they had sex with in the last 12 months prior to the survey date.

This information was used to create the variable of multiple sexual partners "Sexual partner". It was coded as 0 if the respondent had sexual intercourse with the regular sexual partner. The variable was coded as 1 if the respondent had sexual intercourse with one person other than her regular sexual partner and it was coded as 2 if the respondent had sexual intercourse with two or more people other than her regular sexual partner.

The respondents were asked whether they have ever heard of an illness called AIDS, they responded with either yes or no. This information was used to form the variable 'Ever heard of AIDS" and it was coded as 0 if they responded with yes and coded as 1 if they responded with no. The respondents were asked whether they have been tested to see if they have the AIDS virus and they had to reply with either yes or no. This information was used to form the variable "Ever tested for AIDS" and it was coded as 0 if they have ever tested for the AIDS virus and it was coded as 1 if the respondents have never tested for the AIDS virus.

The respondents were asked whether they had any STD in the last 12 months prior to the survey date and had to respond with either yes or no. This information was used to create the variable "Had STD in the last 12 months" and it was coded as 0 if the respondent replied that she 
Table 1: Summary Statistics of the Independent Variables

\begin{tabular}{|c|c|c|c|}
\hline Covariate & Categories & $\begin{array}{l}\text { Age at first sex } \\
16 \text { and below } \\
\text { Number ( \% ) }\end{array}$ & $\begin{array}{l}\text { Over } 16 \\
\text { Number ( \%) } \\
\end{array}$ \\
\hline Residence & $\begin{array}{l}\text { Urban } \\
\text { Rural }\end{array}$ & $\begin{array}{ll}453 & (28.3) \\
1776(38.8)\end{array}$ & $\begin{array}{l}1150(71.7) \\
2804(61.2)\end{array}$ \\
\hline Age at first marriage & $\begin{array}{l}\text { Over } 18 \\
18 \text { and below }\end{array}$ & $\begin{array}{l}387(17.0) \\
1249(50.7)\end{array}$ & $\begin{array}{l}1895(83.0) \\
1214(49.3)\end{array}$ \\
\hline Education level & $\begin{array}{l}\text { Higher } \\
\text { Secondary } \\
\text { Primary } \\
\text { No education }\end{array}$ & $\begin{array}{lr}42 & (12.4) \\
703 & (28.1) \\
1421 & (43.9) \\
63 & (60.6)\end{array}$ & $\begin{array}{lr}298 & (87.6) \\
1800 & (71.9) \\
1815 & (56.1) \\
41 & (39.4)\end{array}$ \\
\hline Sexual partners & $\begin{array}{l}\text { Zero } \\
\text { One } \\
\text { Two or more }\end{array}$ & $\begin{array}{lr}1503 & (35.0) \\
639 & (38.8) \\
61 & (38.6)\end{array}$ & $\begin{array}{l}2794(65.0) \\
1009(61.2) \\
97 \quad(61.4)\end{array}$ \\
\hline Ever heard of AIDS & $\begin{array}{l}\text { Yes } \\
\text { No }\end{array}$ & $\begin{array}{l}2090(35.3) \\
138 \quad(54.5)\end{array}$ & $\begin{array}{l}3838(64.7) \\
115 \quad(45.5)\end{array}$ \\
\hline Ever tested for AIDS & $\begin{array}{l}\text { Yes } \\
\text { No }\end{array}$ & $\begin{array}{l}1556(33.8) \\
673 \quad(42.5)\end{array}$ & $\begin{array}{l}3044(66.2) \\
910\end{array}$ \\
\hline Had STD in the last 12 months & $\begin{array}{l}\text { Yes } \\
\text { No }\end{array}$ & 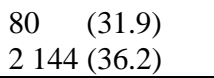 & $\begin{array}{l}171(68.1) \\
3778(63.8)\end{array}$ \\
\hline
\end{tabular}

had STD in the last 12 months prior to the survey date and 1 if she replied with a no. Data that contained missing values or values that were out of range were not included in the analysis.

\section{Variables}

\section{Independent variables}

The independent variables considered are place of residence, age at first marriage, level of education, multiple sexual partners, knowledge of Acquired Immunodeficiency Syndrome (AIDS) (i.e. ever heard of AIDS), testing of AIDS (i.e. ever tested for AIDS) and Sexually Transmitted Disease (STD). STD refers to whether the woman had STD in the last 12 months prior to the survey date. A summary of the statistics of these factors is provided in Table 1.

\section{Dependent variable}

The dependent variable is binary and is the early sexual intercourse debut status coded as 1 if the woman had her sexual intercourse debut at age 16 or below and 0 had her sexual intercourse debut after the age of 16 years. Status refers to whether the woman had her sexual intercourse debut at age 16 or below or had her sexual intercourse debut after the age of 16 years.

\section{Statistical model}

Suppose $y_{i j k}$ represents the status (status refers to whether the woman had her sexual intercourse debut at age 16 or below or had her sexual intercourse debut after the age of 16 years) of age at sexual debut $k$ for the $i$ th woman in the $j$ th EA

$(i=1,2,3 \ldots, 7624 ; j=1,2,3, \ldots ., 400$;

$k=0$ or 1$)$ and $X_{i j k}$ is the covariate vector

for the woman with the corresponding fixed effect coefficient vector $\beta$. The dependent (response) variable $y_{i j k}$ takes the value 1 if the woman had her sexual intercourse debut at age 16 years or below and 0 otherwise. 
Table 2: Results of Model I and Model II

\begin{tabular}{|c|c|c|c|c|c|}
\hline \multicolumn{2}{|l|}{ Independent variables } & \multirow{2}{*}{$\begin{array}{l}\text { Model I } \\
\text { Coefficient } \\
\text { (S.E) }\end{array}$} & \multirow{2}{*}{ P-value } & \multirow{2}{*}{$\begin{array}{l}\begin{array}{l}\text { Model II } \\
\text { Coefficient } \\
\text { (S.E) }\end{array} \\
0(-)\end{array}$} & P-value \\
\hline \multirow[t]{2}{*}{ Residence } & Urban & & & & \\
\hline & Rural & $0.29(0.04)$ & $<0.001$ & $0.07(0.05)$ & 0.192 \\
\hline \multirow[t]{2}{*}{ Age at first marriage } & Over 18 & $0(-)$ & & $0(-)$ & \\
\hline & 18 and below & $0.97(0.04)$ & $<0.001$ & $0.89(0.04)$ & $<0.001$ \\
\hline \multirow[t]{4}{*}{ Education level } & Higher & $0(-)$ & & $0(-)$ & \\
\hline & Secondary & $0.58(0.09)$ & $<0.001$ & $0.20(0.12)$ & 0.088 \\
\hline & Primary & $1.00(0.09)$ & $<0.001$ & $0.56(0.12)$ & $<0.001$ \\
\hline & No education & $1.43(0.15)$ & $<0.001$ & $1.05(0.18)$ & $<0.001$ \\
\hline \multirow[t]{3}{*}{ Sexual partners } & Zero & $0(-)$ & & $0(-)$ & \\
\hline & One & $0.10(0.04)$ & 0.006 & $0.10(0.05)$ & 0.069 \\
\hline & Two or more & $0.10(0.10)$ & 0.350 & $-0.13(0.18)$ & 0.466 \\
\hline \multirow[t]{2}{*}{ Ever heard of AIDS } & Yes & $0(-)$ & & $0(-)$ & \\
\hline & No & $0.49(0.08)$ & $<0.001$ & $0.31(0.10)$ & 0.003 \\
\hline \multirow[t]{2}{*}{ Ever tested for AIDS } & Yes & $0(-)$ & & $0(-)$ & \\
\hline & No & $0.23(0.04)$ & $<0.001$ & $0.04(0.05)$ & 0.495 \\
\hline \multicolumn{6}{|l|}{18 and above } \\
\hline \multirow[t]{2}{*}{ Had STD in the last 12 months } & Yes & $0(-)$ & & $0(-)$ & \\
\hline & No & $0.12(0.08)$ & 0.159 & $0.06(0.10)$ & 0.534 \\
\hline
\end{tabular}

The dependent variable is binary and can be modeled by standard logistic regression models or probit models. However, in here the alternative modeling strategy of a probit link function $P\left(y_{i j k}=1 / X_{i j k}=x_{i j k}\right)=\Phi\left(x_{i j k}^{\prime} \beta_{k}\right) \quad$ is used for analysis of data where $\Phi($.$) is the$ cumulative distribution function of the standard normal distribution while $x_{i j k}^{\prime} \beta_{k}$ is called the probit score or index (or linear predictor) and $\beta_{k_{s}}$ are the parameters that are typically estimated by the method of maximum likelihood. Probit models are amongst the most widely used of the family of generalised linear models in the case of dichotomous dependent variable ${ }^{12}$.

In the first stage separate probit models are fitted for each of the independent variables forming the univariate probit models and in the second stage all the independent variables added simultaneously into the probit model forming the probit model with multiple independent variables. Data analysis was done in STATA 11 statistical software package.

\section{Model I: Univariate probit model}

Univariate probit model refers to the model built with one dependent variable and one independent variable. The probit model described above was used to compute the univariate probit models.

\section{Model II: Probit model with multiple independent variables}

A probit model with multiple independent variables refers to the model built with one dependent variable and two or more independent variables. The probit model described above was used to compute the probit model with multiple independent variables.

\section{Results}

Summary of statistics of the independent variables is illustrated in Table 1 and the specific risk factors from Model I and Model II are demonstrated in Table 2. 


\section{Descriptive statistics}

A summary statistics of the variables is provided in Table 1. Of the 7,624 women that participated in the LDHS 2009, 1,116 (14.6\%) of them never had sexual intercourse whereas $325(4.3 \%)$ had their first sexual intercourse at first marriage and the remaining 6,183 (81.1\%) already had sexual intercourse. Over a third $36.1 \%$ of the women in Lesotho had their first sexual intercourse at age 16 or below. Of those who had sexual intercourse at a young age (16 or less) $1,776(79.7 \%)$ were residing in rural areas and $453(20.3 \%)$ of them were staying in urban areas.

\section{Results from Model I}

The results of Model I are illustrated in Table 2. The results from the univariate probit analysis show that place of residence, age at first marriage, level of education, multiple sexual partners, knowledge of AIDS and testing of AIDS are significantly associated with early age at first sexual intercourse.

The woman who stays in a rural area is at risk to have first sexual intercourse at a young age as compared to a woman who stays in an urban area $(\mathrm{p}<0.001)$. In addition, women who had their sexual debut at a young age are less likely to be married at age above 18 years $(\mathrm{p}<0.001)$, they are at risk of being married at age 18 or below than those who had their sexual debut at an older age.

Women who had their sexual debut at a young age are at risk of not being educated as compared to those who had their sexual debut at an older age $(\mathrm{p}<0.001)$. They are more likely to have multiple sexual partners other than those who had sexual debut at age above 16 years $(\mathrm{p}=0.006$ for one sexual partner $\& p=0.350$ for two or more sexual partners). Moreover, women who had their first sexual intercourse at a young age are likely not to have heard about AIDS $(p<0.001)$ and have never tested for AIDS $(\mathrm{p}<0.001)$. The results further show that women who had early sexual intercourse are likely to have STDs as compared to women who had late sexual intercourse but not significant $(\mathrm{p}=0.159)$.

\section{Results from Model II}

The results of Model II are illustrated in Table 2. The results from the probit model with multiple independent variables show that age at first marriage, level of education and knowledge of AIDS are significantly associated with age at first sexual intercourse. Women who had early sexual intercourse are significantly at risk of being married at age 18 or below than women who had late sexual intercourse $(p<0.001)$. It was found that women who have had their sexual debut at a young age are at the highest risk of not being educated as compared to those who had their sexual debut at age above 16 years $(\mathrm{p}<0.001)$.

Furthermore, those who had their first sexual intercourse at a young age are at a significant risk of not knowing (or have heard) about the worldwide endemic AIDS disease as compared to those who had their first sexual intercourse at an older age $\quad(p=0.003)$.

\section{Discussion}

The factors associated with entering into sexual intercourse at a young age have been investigated including; the behaviour of women post their sexual debut. From the univariate analysis it was identified that place of residence, age at first marriage, level of education, multiple sexual partners, knowledge of AIDS and testing of AIDS were risk factors of early age at first sexual intercourse. However, the results from model II showed that age at first marriage, level of education and knowledge of AIDS were related to age at first sexual intercourse.

The majority of women in Lesotho who have committed into sexual intercourse at a young age come from rural areas, this could happen because rural areas are less developed as compared to urban areas.

The majority of the women who participated in the study were married at age 18 years or below $(52.5 \%)$. At the age of 18 years children should be doing their final year of schooling and preparing for tertiary education. At the age of 18 years children are not mature to enter into a marriage and are likely to drop out of school because they 
will be in a marriage. Dropping out of school contributes to high level of illiteracy for the country which becomes a high risk because a country with high level of illiterate people will develop slowly economically.

Lack of education is a challenge as well as access to health care facilities. According to the Lesotho government education is compulsory between the ages 6 and 13 years ${ }^{15}$. The chances are high that the children will not continue with school when they turn 14 years of age. The current policy on compulsory age of 6 to 13 years for education should be increased to the age of 18 years. Children are not educated about sex and the consequence of this is engaging in sex at a young age. Unprotected sex (e.g. not using condoms) and the advantages of sex education is using contraceptives and the use of protection (such as condoms) when engaging into a sexual intercourse. Also, parents are shy and reluctant to talk to their children about sex.

More than a quarter $(26.3 \%)$ of the women had sexual debut at a young age and were married at age 18 or below implying that they either stopped attending school or felt pregnant while they were young and this may lead to high prevalence of teenage pregnancy. This is supported by the results as it was found that women who had their first sexual intercourse at a young age are not likely to reach the highest level of education. Education is a major tool used to develop people and is a weapon to fight poverty. Women who become mothers at a young age curtail education and have limited access to job opportunities $^{9}$ and this leads to poverty. If women are not developed through education the risk of childhood morbidity and mortality is increased.

Knowledge of AIDS where the respondents were asked whether they have heard about AIDS is a significant predictor in both the univariate probit analysis and the probit analysis with multiple independent variables. This implies that women who entered into their first sexual intercourse at a young age did not have knowledge about AIDS and do not know the implications thereof. It is surprising that the majority of women in Lesotho still have not heard about AIDS which is the most popular disease in the world.
The Center for Disease Control and Prevention (CDC) in Lesotho has been collaborating with the Ministry of Health and Social Welfare since 2007 to support improvement in public health policies, services and capacity development ${ }^{14}$. One of the responsibilities of CDC Lesotho is to focus on HIV/AIDS counselling and testing. According to CDC Lesotho, they have improved access to HIV/AIDS care and treatment, bolstered prevention programmes and strengthened health systems $^{14}$. Despite the achievements reported by CDC Lesotho, approximately $54.5 \%$ of the women who had early sexual debut did not have knowledge of AIDS. By 2010 HIV (33\%) was the leading cause of death in Lesotho. Although CDC in Lesotho has reported that they have improved access to HIV/AIDS care and treatment, they should extend this HIV/AIDS programme to different areas in Lesotho and prioritise young people or youth.

\section{Limitations}

Sexual intercourse is not defined in the LDHS 2009 questionnaire and the respondents could have understood it differently. The study was limited to the risk factors associated with early sexual debut and sexual behaviour post early sexual debut. There could be other factors associated with age at first sexual intercourse or causes of early sexual debut. There may be documents that are informative regarding health programmes, education programmes and age at marriage, but they are not published online by the Lesotho government.

\section{Conclusion and Recommendations}

It has been shown that the risks of entering into sexual intercourse at a young age are that girl children will likely enter into marriage at age 18 years or below, they are likely to be less educated and they do not have knowledge of the chronic disease HIV/AIDS. It is very risky for girls to get married at age 18 years or below because at that age they should still be attending school. Their chances of getting worthy jobs and having decent lives become slim and will likely suffer from poverty. They are most likely to fall pregnant and 
stop attending school thereby contributing to high level of illiteracy and poverty.

Delaying entry into sexuality could be safer and more secure to protect the sexual and reproductive health ${ }^{7}$ in young women. Previous research reported that sexual and reproductive health programmes that advocate abstinence only will have few positive effects on young people ${ }^{3}$. The most efficient programmes are those that combine sexual abstinence and provision of information and contraception services ${ }^{3}$.

Education can be used as a strategy to delay early entry into sexual intercourse, the more time women spend at school the less likely that they can engage in sexual intercourse. Health programmes can be integrated into the education syllabus and be closely monitored by the government of Lesotho. Also, extra mural activities such as sport, music, drama and debate can be used to fight early sexual debut in children and the children should be encouraged to partake in these activities. These activities will keep them busy rather than doing nothing.

Women should be discouraged to enter into marriage at a young age (age 18 or less) and be encouraged to focus on education. The government of Lesotho should emulate democratic countries such as South Africa in developing legislation similar to the South African School Act that makes schooling compulsory for children aged 7 to 15 years. However, the Lesotho government should increase the cut-off point of school age to 18 year instead of 15 years because it is expected that the age of 18 years is when a child should be doing his/her last grade at school. Furthermore, the government of Lesotho should develop a policy that will allow pregnant teenagers to continue attending school while pregnant.

\section{Acknowledgements}

Authors acknowledge the funders of the survey and the Government of Lesotho for allowing us to use the data. In addition, we wish to thank the funders of the survey and the people of Lesotho who opened their doors for Data Collectors and cooperated by giving out some private information.

\section{Contribution of Authors}

Below are the authors and their contributions to the manuscript. All authors mentioned approved the manuscript.

Tshaudi Motsima: Conceived, designed the study and prepared the manuscript. Requested and analysed data.

Jean-Claude Malela-Majika: Reviewed the manuscript and made the input to the methodology.

\section{Reference}

1. Oxford Dictionary of English. 2010. New York: Oxford University Press. pp. 1632.

2. Dickson N, Charlotte P, Peter H, Phil S. First sexual intercourse: age, coercion, and later regrets reported by a birth cohort. BMJ 1998; 316: 29-33.

3. Yodé M, LeGrand T. Association between age at first sexual relation and some indicators of sexual behaviour among adolescents, African Journal of Reproductive Health 2012; 16(2): 173-188.

4. Zuma K, Setswe G, Ketye T, Mzolo T, Rehle T, Mbelle N. Age at first sexual debut: A determinant of multiple partnership among South African youth, African Journal of Public Health 2010; 14(2): 4754.

5. Heath24. Transmission through sexual acts. Available: http://www.health24.com/Medical/HIV-

AIDS/Transmission-of-HIV/Transmission-throughsexual-acts-20120721. 2013.

6. Kaplan DL, Jones EJ, Olson EC, Yunzal-Butler CB. Early age of first sex and health risk in an urban adolescent population. Journal School of Health 2012; 83: 350-356.

7. Yodé M. Association between age at first intercourse, sexual behaviour and sexually transmitted infections among adolescents. Population Association of America 2010 Annual Meeting Program, Poster Session 6(43) 2010; pp. 1-5.

8. UNAIDS. 2011 high level meeting on AIDS. Available: http://www.unaidsrstesa.org/region/regionalprofile/2011-high-level-meeting-aids. 2013.

9. Lesotho: Ministry of Health and Social Welfare. Lesotho Demographic and Health Survey 2009. Maseru: ICF Macro; 2010. pp.74-75.

10. Harrison A, Cleland J, Gouws E, Frohlich J. Early sexual debut among men in rural South Africa: Heightened vulnerability to sexual risk?, $B M J 2005$; 81: 259-261.

11. Mueller TE, Lorrie EG, Aniket K. The association between sex education in youth's engagement in sexual intercourse, age at first intercourse, and birth control use at first sex. Journal of Adolescent Health 2007; 42(1): 89-96. 
12. Hahn ED, Soyer R. Probit and logit models: Differences in the multivariate realm. Submitted to The Journal of the Royal Statistical Society, Series (B) 2005.

13. South Africa. Lovelife. Available: http://www.lovelife.org.za. 2013.

14. Center for Disease Control and Prevention Lesotho.
Available:http://www.cdc.gov/globalhealth/ countries/lesotho/pdf/lesotho_factsheet.pdf. 2016.

15. Lesotho Government. Available: http://www.gov.l /gov_webportal/education/education_menu.html. 2016. 